\title{
Site-specific occurrence of nonmelanoma skin cancers in patients with cutaneous melanoma
}

\author{
RE Neale ${ }^{*, 1,3}$, D Forman², MFG Murphy' and DC Whiteman ${ }^{3}$ \\ 'Childhood Cancer Research Group, 57 Woodstock Rd, Oxford OX2 6HJ, UK; ${ }^{2}$ Centre for Epidemiology and Biostatistics, University of Leeds \& Northern \\ and Yorkshire Cancer Registry and Information Service, Arthington House, Hospital Lane, Leeds LSI6 6QB, UK; ${ }^{3}$ Division of Population Studies and \\ Human Genetics, Queensland Institute of Medical Research, Post Office, Royal Brisbane Hospital, QLD 4029, Australia
}

\begin{abstract}
In a registry-based case-control study, we compared the site-specific occurrence of nonmelanoma (keratinocytic) skin cancers among patients with cutaneous melanoma cases (cases, $n=3774$ ) and solid tumours (controls, $n=349$ 923), respectively. Overall, patients with melanoma were almost five-fold more likely to develop keratinocytic cancers compared with solid tumour controls (adjusted OR 4.7, 95\% Cl 4.I-5.3), but the risks varied depending upon the site of melanoma. Whereas patients with melanoma of the head and neck had similarly increased risks of keratinocytic cancers across all body sites, patients with melanoma of the trunk were significantly more likely to develop keratinocyte cancer diagnosed on the trunk (adjusted OR I2.5, 95\% Cl 7.2-20.2) than on the head and neck (adjusted OR 3.0, 95\% Cl 2.2-4.3). Similar colocalisation of skin tumours was observed for patients with melanomas of the lower limb. These findings provide support for the hypothesis that skin cancers at different anatomical sites may arise through different causal pathways.

British Journal of Cancer (2005) 93, 597-60I. doi:I0.1038/sj.bjc.6602745 www.bjcancer.com

Published online 16 August 2005

(c) 2005 Cancer Research UK
\end{abstract}

Keywords: cutaneous melanoma; basal cell carcinoma; skin neoplasms; squamous cell carcinoma; nonmelanoma skin cancer; keratinocytic cancer

While there is consensus that sunlight is the principal environmental cause of melanomas, their anatomical distribution precludes a simple association with sunlight. Some sites (e.g. trunk) typically have modest levels of sun exposure yet have high melanoma incidence, whereas other highly exposed sites (e.g. hand) have lower melanoma incidence (Green et al, 1993; Bulliard et al, 1997).

One explanation for these observations may be that the causes of melanoma vary depending upon the anatomical site of the melanocyte The 'divergent pathway' model proposes that the relative contribution of genetic and environmental exposures differs according to the anatomic location of the melanoma (Whiteman et al, 2003).

The association between sunlight and basal cell carcinoma (BCC) is similarly complex with many lesions occurring on less sun exposed sites, a plateau of incidence with age and a strong association between recreational exposure and risk (Kricker et al, 1995). In contrast to melanoma and BCC, the risk of squamous cell carcinoma (SCC) rises monotonically with exposure to the sun.

Patients with melanoma are known to be at a substantially increased risk of the nonmelanoma skin cancers (NMSC) BCC and SCC (Wassberg et al, 1996; Levi et al, 1997a; Hemminki et al, 2003; Crocetti and Carli, 2004) and the converse is also true (Levi et al, 1997b, 1998; Wassberg et al, 1999; Bower et al, 2000; Maitra et al, 2005). However, it is not known whether the association between melanoma and NMSC varies according to the anatomical site. We

*Correspondence: Dr RE Neale; E-mail: rachel.neale@ccrg.ox.ac.uk Received 12 April 2005; revised 22 June 2005; accepted 20 July 2005; published online 16 August 2005 chose to explore this question using a record-linkage study from a British cancer registry. We hypothesised that because of shared risk factors, patients with melanoma of the head or neck would be at particularly high risk of nonmelanoma skin cancer and specifically SCCs.

\section{MATERIALS AND METHODS}

We conducted a registry-based case-control study to test the hypothesis that the risk of site-specific NMSC among people with melanoma varies according to the site of the melanoma. People with melanoma (cases) were compared with people with a solid tumour other than melanoma (controls) for the prevalence of NMSC.

This data-linkage study was conducted using records obtained from the Northern \& Yorkshire Cancer Registry and Information Service (NYCRIS). Northern \& Yorkshire Cancer Registry and Information Service is responsible for the registration of all malignant cancers in the former Northern and Yorkshire NHS regions and covers a population of 6.4 million. This study was approved by the NYCRIS Advisory Group.

\section{Case selection}

Eligible cases were all notifications of invasive melanoma (ICD10 C43) among people aged 15 years and older diagnosed between January 1986 and December 2000 (99\% of diagnoses were histologically confirmed and melanoma registration is estimated to be at least $88 \%$ complete (Stefoski Mikeljevic et al, 2003). We 
excluded all cases registered with more than one cancer, apart from NMSC. For the primary analysis, we restricted cases to patients with primary invasive melanoma of the superficial spreading or nodular histological subtypes. We therefore excluded patients diagnosed with metastatic melanomas, lentigo maligna melanomas and rare histological subtypes of melanoma that have not been associated with sun exposure (e.g. acral lentiginous melanoma, desmoplastic melanoma, spindle cell melanoma, etc.) and those without a histological subtype.

\section{Control selection}

Controls were all people diagnosed with a nonskin solid tumour (ICD 10 codes C00-C75, excluding C43-C44) and diagnosed during the same time interval as the cases. We excluded controls diagnosed with more than one tumour (apart from NMSC) during the study interval, and those who had a diagnosis in childhood (age $<15$ years)

\section{Data collection}

Age and sex of cases and controls were captured from the registry records, as well as the date of diagnosis and site of melanoma or other solid tumour where available. Notifications of cancers were ascertained from pathology reports, medical records of National Health Service and independent hospitals and hospices and death certificates. An examination of completeness of NYCRIS skin cancer registration in 1994 demonstrated that $83 \%$ of NMSC were captured (Stefoski Mikeljevic et al, 2003).

NYCRIS staff routinely check all new registrations to link second (or subsequent) cancers occurring in previously registered patients. A match is made on the basis of name, date of birth and postcode of address where possible. Where there are common alternative spellings or abbreviations for a name these are also explored. If a patient has already been registered, the site and type of tumour is examined to determine if the new tumour is a new primary or represents additional information regarding a previous registration. Where the sites are different, a new registration is made. If the sites are the same, the pathological type of tumour is examined - the same type is not reregistered unless there is explicit evidence that there is a new primary. This routine linkage information was used to identify occurrence of NMSC (ICD10 C44) (specifically BCC, SCC and carcinoma in situ (CIS)) among all melanoma cases and other solid tumour controls.

\section{Statistical analysis}

The primary aim of this analysis was to compare the prevalence of NMSC among patients with melanoma and other solid tumours, and to compare the magnitude of the associations according to the anatomical site of the melanoma. We therefore categorised melanoma cases into those whose melanoma occurred on the trunk, the head and neck, the upper limbs and the lower limbs and compared each group of cases to the control series. For this analysis, we were interested in the occurrence of all NMSC; hence, there was no reason a priori to specify whether the event of NMSC occurred before or after the event of melanoma or solid tumour diagnosis. We therefore calculated the odds ratio (OR) and $95 \%$ confidence interval $(95 \% \mathrm{CI})$ to estimate the strength of association between period prevalence of NMSC and site of melanoma. The OR disregards any temporal relationship between the lesions. We calculated the OR using multivariable polytomous logistic regression with patients having tumours other than melanoma serving as the reference group. If more than one type of NMSC was registered for a patient (e.g. one BCC and one SCC), then we included each type in the respective NMSC type-specific analysis. If more than one NMSC of the same type was recorded, then only one of these contributed to the analysis.
In all models we adjusted for sex and age (in single years) at diagnosis of melanoma (for cases) or solid tumour (for controls), and we also included an age-squared term to adjust for residual nonlinear effects of age. All analyses were performed with SAS software (release 8.2; SAS Institute, Cary, NC, USA).

\section{RESULTS}

We identified 349923 control patients who had one tumour other than melanoma diagnosed between 1 January 1986 and 31 December 2000. The most commonly diagnosed tumours were those of the breast (ICD10 C45) and colon/rectum/anus (ICD10 C18-C21), each of which accounted for $14 \%$ of the registered tumours. The mean age of diagnosis was 69 years (range 15-111) and $50 \%$ of patients were male (Table 1 ).

There were 7084 case patients notified with cutaneous melanoma during the study period. After excluding those with incomplete notifications (missing anatomical site 491, missing histological type 2311) or ineligible histological types (LMM 279, other 229), there were 3774 patients with invasive melanomas with known site and eligible histological subtype (53\% of total) for the primary analysis. Median age at melanoma diagnosis was 54 years, but was significantly higher for people with melanoma of the head and neck (69 years) compared to people with melanomas of the trunk, upper or lower limbs (53 years) $(P<0.001$, Wilcoxon test).

The overall prevalence of NMSC was $7 \%$ among melanoma cases and $3 \%$ among other solid tumour controls (crude OR 2.5, 95\% CI 2.2-2.8). Adjusting for sex and the linear and nonlinear effects of age substantially increased the OR (adjusted OR 4.7, 95\% CI $4.1-$ 5.3). Among melanoma cases with NMSC, $68 \%$ were BCCs, $16 \%$ were SCCs and $16 \%$ were CIS. In contrast, among controls with

Table I Descriptive statistics for melanoma cases and solid tumour controls

\begin{tabular}{|c|c|c|}
\hline Cases & All melanomas ${ }^{\mathbf{a}}$ & Eligible melanomas ${ }^{\mathrm{b}}$ \\
\hline \multicolumn{3}{|l|}{ Head and neck } \\
\hline$N(\%)$ of all melanomas & $1193(19)$ & $512(14)$ \\
\hline$N(\%)$ female & $632(53)$ & $268(52)$ \\
\hline Mean (median) age at diagnosis & $67(7 \mid)$ & $64(69)$ \\
\hline$N(\%)$ with keratinocyte cancers & $146(12)$ & $64(13)$ \\
\hline \multicolumn{3}{|l|}{ Trunk } \\
\hline$N(\%)$ of all melanomas & $1550(24)$ & $1018(27)$ \\
\hline$N(\%)$ female & $593(38)$ & $386(38)$ \\
\hline Mean (median) age at diagnosis & $52(53)$ & $52(53)$ \\
\hline$N(\%)$ with keratinocyte cancers & $97(6)$ & $65(6)$ \\
\hline \multicolumn{3}{|l|}{ Upper limbs } \\
\hline N (\%) of all melanomas & $1189(19)$ & $749(20)$ \\
\hline$N(\%)$ female & $765(64)$ & $487(65)$ \\
\hline Mean (median) age at diagnosis & $54(54)$ & $53(52)$ \\
\hline$N(\%)$ with keratinocyte cancers & $79(7)$ & $55(7)$ \\
\hline \multicolumn{3}{|l|}{ Lower limbs } \\
\hline$N(\%)$ of all melanomas & $2432(38)$ & $1495(40)$ \\
\hline$N(\%)$ female & $1944(80)$ & $1205(8 \mid)$ \\
\hline Mean (median) age at diagnosis & $55(55)$ & $53(53)$ \\
\hline$N(\%)$ with keratinocyte cancers & $142(6)$ & $92(6)$ \\
\hline \multicolumn{3}{|l|}{ Controls } \\
\hline \multicolumn{3}{|l|}{ Solid tumours } \\
\hline N & 349923 & \\
\hline N (\%) female & $173795(50)^{c}$ & \\
\hline Mean (median) age at diagnosis & $69(70)$ & \\
\hline$N(\%)$ with keratinocyte cancers & $10754(3)$ & \\
\hline
\end{tabular}

${ }^{a}$ Excluding those for whom site was unknown. ${ }^{b}$ Site known, eligible histological type (not LMM, acral lentiginous, desmoplastic or other ineligible types). 'Sex missing for |5I patients. 
keratinocyte cancers, approximately $80 \%$ were BCCs, $20 \%$ were SCCs and only one patient was diagnosed with CIS.

Associations between NMSC and melanomas at each anatomical site are presented in Table 2. On crude analysis, NMSC were more strongly associated with melanomas of the head and neck (OR 4.5) than melanomas of the trunk, arms or legs (ORs 2.1-2.5) (Table 2). After tightly adjusting for age and sex, however, patients with melanomas at all sites were approximately five-fold more likely to be diagnosed with NMSC than controls, with little variation in the magnitude of associations by anatomical site of melanoma. Similar associations were observed when analyses were restricted to specific types of NMSC (Table 2).

Further analyses of the body site distribution of NMSC and melanomas provided some evidence for anatomical colocalisation of these different types of skin cancer (Table 3). This was most apparent on the trunk, whereby patients with melanomas of the trunk were significantly more likely to have an NMSC diagnosed on the trunk (adjusted OR 12.5, 95\% CI 7.2-20.2) or upper limb (adjusted OR 9.8, 95\% CI 4.8-19.8) than the head and neck (adjusted OR 3.0, 95\% CI 2.2-4.3). Similar patterns of colocalisation of NMSC, particularly BCCs, were observed for patients with melanomas on the upper and lower limbs. The risk of NMSC in melanoma patients at sites other than those where the melanoma arose (with the exception of the trunk and upper limb where both sites experienced a marked elevation of risk in the presence of melanoma at either site) was consistently about four-fold higher than the risk of NMSC in patients with other solid tumours.

\section{DISCUSSION}

This study confirms that people with a diagnosis of melanoma have substantially higher risks of NMSC compared to patients with other types of cancer. This strong association was not unexpected and is similar in magnitude to risks reported in other European record linkage studies (Wassberg et al, 1996; Levi et al, 1997a; Kroumpouzos et al, 2000; Hemminki et al, 2003; Crocetti and Carli, 2004).

Our a priori hypothesis that patients with melanomas of the head and neck would have higher overall occurrence of NMSC than patients with melanomas of the trunk was only partially supported by these data. On crude analysis, patients with melanomas of the head and neck had substantially larger associations with NMSC than patients with melanomas at other body sites. After adjusting for linear and nonlinear effects of age, the associations between NMSC and melanoma at all body sites became markedly stronger and the apparent discrepancy between melanomas at different sites was removed.

The effects of adjusting for age were considerable; yet interpreting these effects is not straightforward. Two explanations may be considered. On the one hand, the analyses could indicate that the relationship between melanoma and NMSC was negatively confounded by age. Alternatively, if age is a necessary causal factor in the development of head and neck melanomas, as suggested by the more than 10 year age difference between patients with melanoma of the head and neck $v s$ the trunk in this data set and others (Elwood and Gallagher, 1998; Bulliard, 2000), then by adjusting for age, we may actually have introduced bias to the risk estimates (Hernan et al, 2002). This issue cannot be resolved by further interrogation of these data.

Our new finding of colocalisation of melanoma and BCC at sites other than the head and neck has not been previously reported. To our knowledge, only one other study has investigated this possibility, although it was hampered by a short duration of follow-up and a small sample size calling the observed null result into question (Kroumpouzos et al, 2000). Assuming that our finding was not the result of chance, the question arises as to why melanomas and BCC should tend to arise on the same anatomical
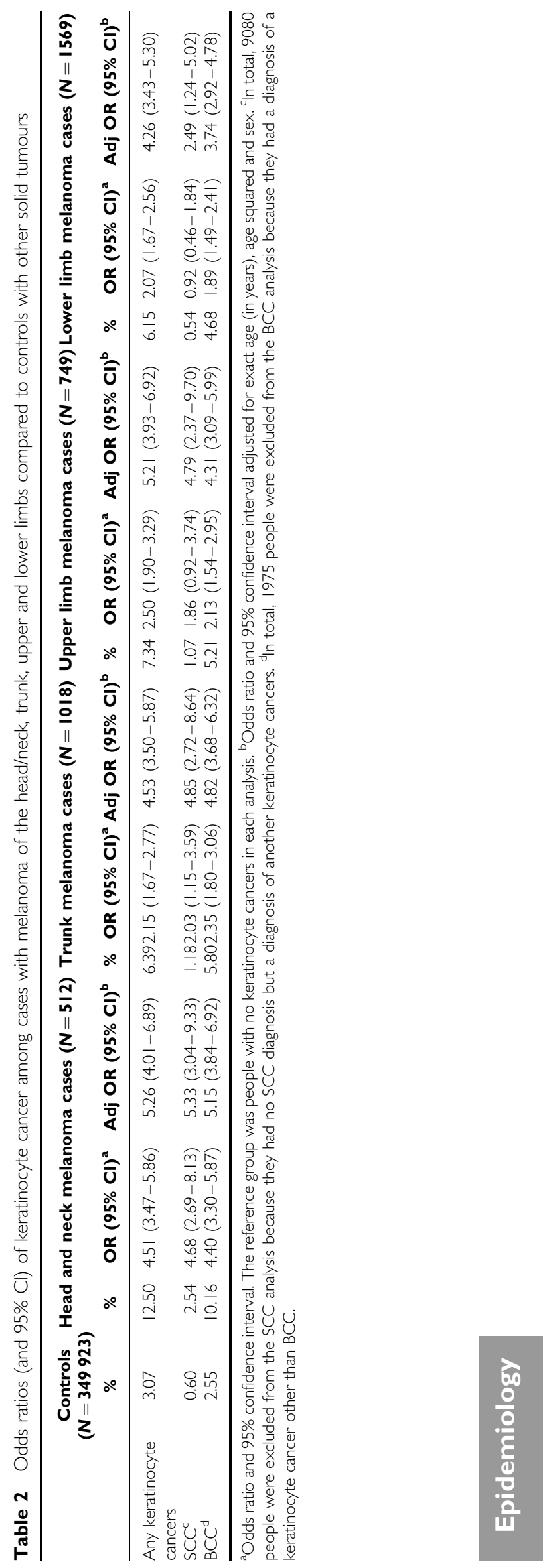


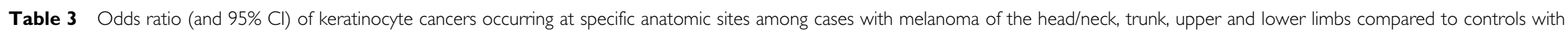
other solid tumours

\begin{tabular}{|c|c|c|c|c|c|c|c|c|c|c|c|c|c|}
\hline \multirow{2}{*}{$\begin{array}{l}\text { Keratinocytic } \\
\text { cancer site }\end{array}$} & \multirow{2}{*}{$\begin{array}{c}\begin{array}{c}\text { Controls } \\
(\mathbf{N}=\mathbf{3 4 9} 923) \\
\%\end{array} \\
\end{array}$} & \multicolumn{3}{|c|}{$\begin{array}{l}\text { Head and neck melanoma cases } \\
\qquad(N=5 \mid 2)\end{array}$} & \multicolumn{3}{|c|}{$\begin{array}{l}\text { Trunk melanoma cases } \\
\qquad(N=1018)\end{array}$} & \multicolumn{3}{|c|}{$\begin{array}{l}\text { Upper limb melanoma cases } \\
\qquad(N=749)\end{array}$} & \multicolumn{3}{|c|}{$\begin{array}{l}\text { Lower limb melanoma cases } \\
\qquad(N=1569)\end{array}$} \\
\hline & & $\%$ & OR $(95 \% \mathrm{Cl})^{\mathrm{a}}$ & Adj OR $(95 \% \mathrm{Cl})^{\mathrm{b}}$ & $\%$ & OR $(95 \% \mathrm{Cl})^{\mathrm{a}}$ & Adj OR $(95 \% \mathrm{Cl})^{\mathrm{b}}$ & $\%$ & OR $(95 \% \mathrm{Cl})^{\mathrm{a}}$ & Adj OR $(95 \% \mathrm{Cl})^{b}$ & $\%$ & OR $(95 \% \mathrm{Cl})^{\mathrm{a}}$ & Adj OR $(95 \% \mathrm{Cl})$ \\
\hline \multicolumn{14}{|l|}{ Head and neck } \\
\hline $\begin{array}{l}\text { All keratinocyte } \\
\text { cancers }\end{array}$ & 2.46 & 10.35 & $4.58(3.44-6.09)$ & $5.33(3.97-7.14)$ & 3.44 & $1.41(1.01-1.98)$ & $3.03(2.15-4.27)$ & 4.141 & $1.71(1.19-2.45)$ & $3.68(2.55-5.3 \mathrm{I})$ & 2.74 & $1.12(0.82-1.53)$ & $2.40(1.75-3.29)$ \\
\hline BCC only ${ }^{d}$ & 2.15 & 9.49 & $4.77(3.53-6.44)$ & $5.58(4.10-7.60)$ & 3.44 & $1.62(1.15-2.28)$ & $3.47(2.45-4.92)$ & 3.341 & $1.57(1.05-2.36)$ & $3.36(2.22-5.08)$ & 2.50 & $1.17(0.84-1.62)$ & $2.44(1.74-3.4 I)$ \\
\hline SCC only & 0.39 & 1.97 & $5.16(2.66-10.01)$ & $5.89(3.02-|1.5|)$ & 0.63 & $1.62(0.72-3.62)$ & $3.89(1.73-8.74)$ & 0.72 । & $1.85(0.77-4.47)$ & $5.23(2.15-|2.7|)$ & 0.28 & $0.73(0.27-1.96)$ & $2.32(0.87-6.24)$ \\
\hline \multicolumn{14}{|l|}{ Trunk } \\
\hline $\begin{array}{l}\text { All keratinocyte } \\
\text { cancers }\end{array}$ & 0.29 & 0.78 & $4.03(1.50-10.82)$ & $4.44(1.66-11.93)$ & 1.77 & $9.22(5.75-14.78)$ & $12.48(7.15-20.19)$ & 1.346 & $6.93(3.70-12.99)$ & $9.87(5.23-|8.6|)$ & 0.80 & $4.14(2.37-7.35)$ & $6.04(3.38-|0.8|)$ \\
\hline BCC only ${ }^{d}$ & 0.17 & 0.88 & $5.16(1.92-13.85)$ & $5.81(2.16-15.62)$ & 1.55 & $9.90(5.43-15.24)$ & $12.32(7.28-20.85)$ & 1.146 & $6.66(3.30-13.43)$ & $9.42(4.64-19.13)$ & 0.78 & $4.53(2.49-8.24)$ & $6.48(3.53-11.90)$ \\
\hline SCC onlyc & 0.03 & 0.00 & $\mathrm{~N} / \mathrm{C}$ & $\mathrm{N} / \mathrm{C}$ & 0.217 & $7.49(1.84-30.44)$ & $11.94(2.86-49.92)$ & 0.145 & $5.14(0.72-36.95)$ & $9.83(1.35-71.58)$ & 0.00 & $\mathrm{~N} / \mathrm{C}$ & $\mathrm{N} / \mathrm{C}$ \\
\hline \multicolumn{14}{|l|}{ Upper limbs } \\
\hline $\begin{array}{l}\text { All keratinocyte } \\
\text { cancers }\end{array}$ & 0.15 & 0.59 & $3.95(1.27-12.27)$ & $4.39(|.40-13.7|)$ & 0.79 & $5.28(2.62-10.64)$ & $9.77(4.81-19.84)$ & 1.077 & $7.19(3.56-14.50)$ & $13.76(6.76-28.00)$ & 0.27 & $1.79(0.67-4.79)$ & $3.56(1.32-9.59)$ \\
\hline BCC only & 0.07 & 0.00 & $\mathrm{~N} / \mathrm{C}$ & $\mathrm{N} / \mathrm{C}$ & 0.63 & $9.66(4.28-21.79)$ & $15.76(6.90-36.02)$ & 0.436 & $6.63(2.12-20.78)$ & $10.62(3.35-33.67)$ & 0.14 & $2.19(0.54-8.81)$ & $3.45(0.85-14.08)$ \\
\hline SCC only ${ }^{c}$ & 0.09 & 0.44 & $5.06(1.26-20.30)$ & $5.90(1.46-23.84)$ & 0.10 & $1.18(0.17-8.43)$ & $2.67(0.37-19.11)$ & 0.141 & $1.62(0.23-11.58)$ & $4.07(0.57-29.09)$ & 0.07 & $0.80(0.11-5.72)$ & $2.16(0.30-15.40)$ \\
\hline \multicolumn{14}{|l|}{ Lower limbs } \\
\hline $\begin{array}{l}\text { All keratinocyte } \\
\text { cancers }\end{array}$ & 0.17 & 0.39 & $2.27(0.56-9.11)$ & $2.49(0.62-10.03)$ & 0.29 & I.7। (0.55-5.32) & $3.85(1.23-12.02)$ & 0.402 & $2.33(0.75-7.25)$ & $3.85(1.25-12.02)$ & 1.74 & | $0.24(6.89-\mid 5.21)$ & ) $4.39(9.59-21.58)$ \\
\hline BCC only & 0.10 & 0.22 & $2.14(0.30-15.30)$ & $2.47(0.35-17.66)$ & 0.31 & $3.03(0.97-9.44)$ & $6.26(|.99-| 9.7 \mid)$ & 0.141 & $1.38(0.19-9.87)$ & $2.22(0.31-15.90)$ & 0.92 & 8.9 & $12.07(6.85-2$ \\
\hline SCC only ${ }^{c}$ & 0.07 & 0.00 & $N / C$ & $\mathrm{~N} / \mathrm{C}$ & 0.00 & $\mathrm{~N} / \mathrm{C}$ & $\mathrm{N} / \mathrm{C}$ & 0.00 & $\mathrm{~N} / \mathrm{C}$ & $\mathrm{N} / \mathrm{C}$ & 0.14 & $1.98(0.49-7.88)$ & $3.27(0.81-13.25)$ \\
\hline
\end{tabular}

adds ratio and $95 \%$ confidence interval. The reference group was people with no keratinocyte cancers in each analysis. ${ }^{\mathrm{b}} \mathrm{Odds}$ ratio and $95 \%$ confidence interval adjusted for exact age (in years), age squared and sex. ${ }^{\mathrm{C}}$ In total, 9080

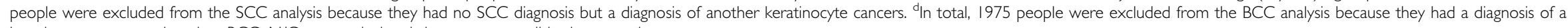
keratinocyte cancer other than BCC. N/C = not calculated due to a zero cell in the control group. 
sites. One possibility is heightened awareness or surveillance of the body site where the first tumour was excised. This possibility is supported by the frequent diagnosis of in situ keratinocyte carcinomas among melanoma patients compared with their virtual absence in controls. Moreover, a recent Australian study has shown a marked increase in the incidence of BCC on less sun exposed body sites when active skin screening is undertaken (Valery et al, 2004).

Although heightened skin cancer surveillance among melanoma patients might partially explain colocalisation, this phenomenon may also reflect common variation in the component causes of both melanoma and BCC arising at different anatomical sites. As with melanoma, the association between sun exposure and BCC is complex and is likely to be modified by genetic factors and the anatomical location of the target cell (Lear et al, 1997a, b; Ramachandran et al, 2001a,b). For both melanoma and BCC, those tumours occurring on the head and neck are more likely to overexpress p53 protein then their truncal counterparts (D'Errico et al, 1997; Whiteman et al, 1998). Similarly, both melanomas and BCC arise at considerably older ages on the head and neck than on the trunk (Ramachandran et al, 2001a). These various observations support the view that melanomas and BCCs occurring on the trunk share similar causes, which appear to differ from those required to induce BCCs and melanomas of the head and neck.

We considered the possibility that our findings may be influenced by other sources of error. Under-registration of NMSC is a potential problem, although recent analyses of the NYCRIS suggest that more than $80 \%$ of NMSC are captured in this

\section{REFERENCES}

Bower CP, Lear JT, Bygrave S, Etherington D, Harvey I, Archer CB (2000) Basal cell carcinoma and risk of subsequent malignancies: a cancer registry-based study in southwest England. J Am Acad Dermatol 42: $988-991$

Bulliard JL (2000) Site-specific risk of cutaneous malignant melanoma and pattern of sun exposure in New Zealand. Int J Cancer 85: 627-632

Bulliard JL, Cox B, Elwood JM (1997) Comparison of the site distribution of melanoma in New Zealand and Canada. Int J Cancer 72: 231-235

Crocetti E, Carli P (2004) Risk of second primary cancers, other than melanoma, in an Italian population-based cohort of cutaneous malignant melanoma patients. Eur J Cancer Prev 13: 33-37

D’Errico M, Calcagnile AS, Corona R, Fucci M, Annessi G, Baliva G, Tosti ME, Pasquini P, Dogliotti E (1997) p53 mutations and chromosome instability in basal cell carcinomas developed at an early or late age. Cancer Res 57: $747-752$

Elwood JM, Gallagher RP (1998) Body site distribution of cutaneous malignant melanoma in relationship to patterns of sun exposure. Int $J$ Cancer 78: $276-280$

Green A, MacLennan R, Youl P, Martin N (1993) Site distribution of cutaneous melanoma in Queensland. Int J Cancer 53: 232-236

Hemminki K, Jiang Y, Steineck G (2003) Skin cancer and non-Hodgkin's lymphoma as second malignancies. Markers of impaired immune function? Eur J Cancer 39: 223-229

Hernan MA, Hernandez-Diaz S, Werler MM, Mitchell AA (2002) Causal knowledge as a prerequisite for confounding evaluation: an application to birth defects epidemiology. Am J Epidemiol 155: 176-184

Kricker A, Armstrong BK, English DR, Heenan PJ (1995) Does intermittent sun exposure cause basal cell carcinoma? A case-control study in Western Australia. Int J Cancer 60: 489-494

Kroumpouzos G, Konstadoulakis MM, Cabral H, Karakousis CP (2000) Risk of basal cell and squamous cell carcinoma in persons with prior cutaneous melanoma. Dermatol Surg 26: 547-550

Lear JT, Smith AG, Bowers B, Heagearty AH, Jones PW, Gilford J, Alldersea J, Strange RC, Fryer AA (1997a) Truncal tumor site is associated with high risk of multiple basal cell carcinoma and is influenced by glutathione $S$-transferase, GSTT1, and cytochrome P450, CYP1A1 genotypes, and their interaction. J Invest Dermatol 108: 519-522

Lear JT, Smith AG, Heagerty AH, Bowers B, Jones PW, Gilford J, Alldersea J, Strange RC, Fryer AA (1997b) Truncal site and detoxifying enzyme population (Stefoski Mikeljevic et al, 2003). Increased surveillance of melanoma patients may increase the likelihood of diagnosing NMSC compared with control patients, but there is no reason to suppose that registration is differentially related to the site of the melanoma.

Another potential source of error stems from the fact that almost half of the melanoma notifications to the registry were excluded from these analyses, mostly due to missing information about the histological type of melanoma that was considered important a priori. We tested the effect of this restriction by reanalysing the data after including all cases with missing histological information. We found no alteration in the pattern of results to those reported in the tables.

In conclusion, these data provide support for the notion that melanomas and BCCs share similar causal factors, but suggest that the associations between different types of skin cancer differ according to the anatomical site of the lesion and the age of the host.

\section{ACKNOWLEDGEMENTS}

Rachel Neale and David Whiteman are supported by a Sidney Sax Fellowship and a Senior Research Fellowship, respectively, from the National Health and Medical Research Council of Australia. We would like to thank Alison Crawford from NYRCRIS for creating a data set for analysis. polymorphisms significantly reduce time to presentation of further primary cutaneous basal cell carcinoma. Carcinogenesis 18: 1499-1503

Levi F, La Vecchia C, Randimbison L, Te VC, Erler G (1997a) Incidence of invasive cancers following cutaneous malignant melanoma. Int J Cancer 72: $776-779$

Levi F, La Vecchia C, Te VC, Randimbison L, Erler G (1998) Incidence of invasive cancers following basal cell skin cancer. Am J Epidemiol 147: $722-726$

Levi F, Randimbison L, La Vecchia C, Erler G, Te VC (1997b) Incidence of invasive cancers following squamous cell skin cancer. Am J Epidemiol 146: $734-739$

Maitra SK, Gallo H, Rowland-Payne C, Robinson D, Moller H (2005) Second primary cancers in patients with squamous cell carcinoma of the skin. Br J Cancer 92: 570-571

Ramachandran S, Fryer AA, Lovatt T, Lear J, Smith AG, Strange RC (2001a) Susceptibility and modifier genes in cutaneous basal cell carcinomas and their associations with clinical phenotype. J Photochem Photobiol B 63: 1 - 7

Ramachandran S, Fryer AA, Smith A, Lear J, Bowers B, Jones PW, Strange RC (2001b) Cutaneous basal cell carcinomas: distinct host factors are associated with the development of tumors on the trunk and on the head and neck. Cancer 92: 354-358

Stefoski Mikeljevic J, Johnston C, Adamson PJ, Wright A, Bishop JA, Batman P, Neal RD, Forman D (2003) How complete has skin cancer registration been in the UK? A study from Yorkshire. Eur J Cancer Prev 12: $125-133$

Valery PC, Neale R, Williams G, Pandeya N, Siller G, Green A (2004) The effect of skin examination surveys on the incidence of basal cell carcinoma in a Queensland community sample: a 10-year longitudinal study. J Invest Dermatol Symp Proc 9: 148-151

Wassberg C, Thorn M, Yuen J, Ringborg U, Hakulinen T (1996) Second primary cancers in patients with cutaneous malignant melanoma: a population-based study in Sweden. Br J Cancer 73: 255-259

Wassberg C, Thorn M, Yuen J, Ringborg U, Hakulinen T (1999) Second primary cancers in patients with squamous cell carcinoma of the skin: a population-based study in Sweden. Int J Cancer 80: $511-515$

Whiteman DC, Parsons PG, Green AC (1998) p53 expression and risk factors for cutaneous melanoma: a case-control study. Int J Cancer 77: 843-848

Whiteman DC, Watt P, Purdie DM, Hughes MC, Hayward NK, Green AC (2003) Melanocytic nevi, solar keratoses, and divergent pathways to cutaneous melanoma. J Natl Cancer Inst 95: 806-812 